\title{
Carlos Aguirre y la intimidad como medio de expresión
}

\author{
Marcelo Gastaldi
}

[Universidad Nacional del Litoral]

Resumen El abordaje que este artículo propone realizar acerca de la obra de Carlos Aguirre será desde un ángulo colateral y, a la vez, paradójico. Por un lado, se trabajará la noción de que la intimidad opera como un canal de comunicación, en relación con el lenguaje. Por otro lado, el concepto de intimidad será considerado como un "territorio interno" que necesita ser reafirmado en la exterioridad. Mediante el análisis de piezas seleccionadas se verá cómo, en definitiva, la intimidad en la obra de Aguirre se manifiesta principalmente a través de los títulos, la textualidad y las puestas en escena durante los conciertos. Se percibirá, además, una articulación entre melodías simples y claras, texturas de tipo canción y una misma idea conceptual. La intimidad se vuelve una manera de concebir la obra.
Summary The approach that this article proposes to take on the work of Carlos Aguirre will be from a collateral and, at the same time, paradoxical angle. On the one hand, the notion that intimacy operates as a channel of communication, in relation to language, will be worked on. On the other hand, the concept of intimacy will be considered as an "internal territory" that needs to be reaffirmed externally. By analyzing selected pieces, it will be seen how, ultimately, intimacy in Aguirre's work is manifested mainly through the titles, textuality and staging during concerts. In addition, an articulation between simple and clear melodies, song-like textures and the same conceptual idea will be perceived. Intimacy becomes a way of conceiving the work. 


\section{INTRODUCCIÓN}

Hablar de la vida y obra de Aguirre fue el germen que se despertó para llevar adelante esta investigación. Esa tentación de dejar un registro fugaz de su existencia, una narrativa ${ }^{1}$ que perdure y nos sobreviva. Ahora bien, ¿sería de gran aporte hablar de su biografía? ¿Ayudaría a entender nuestro objeto de estudio? Son preguntas que no podremos contestar con exactitud, pero sí aventurarnos en algunas hipótesis entendiendo la infinitud de nuestro ejercicio. De todas maneras, lejos de tener un objetivo historicista, nuestra investigación se inserta en el campo de la estética: trata de entender qué proyecta la música de Aguirre a partir del concepto de intimidad. El objetivo de esto, no es decir que Aguirre es el único artista que trabaja para expresarse a través de la intimidad, sino que se trata de entender de qué forma la utiliza. En este sentido, presentaremos un breve recorrido biográfico sobre Aguirre, en la medida en que consideremos pertinentes algunas informaciones para nuestros objetivos.

Carlos Aguirre es oriundo de un pequeño pueblo con características urbanorurales llamado Seguí ${ }^{2}$. En su casa, había un ambiente musical muy intenso, su padre era melómano, y se escuchaban compositores de música clásica, jazz y algo de folclore. A los 5 años empezó a estudiar piano con una profesora llamada Vilma Cargnel. A los I4 años llegó a vivir en la ciudad de Paraná, en donde seguiría la secundaria pero continuando sus estudios con Graciela Reca, que se prolongó hasta dos años después de terminar la escuela. El trabajo con Graciela fue muy profundo, generando en Aguirre un movimiento interno muy fuerte que lo impulsó a tomar con seriedad el camino de la música ${ }^{3}$.

Su infancia en Seguí fue algo que lo marcó hasta el día de hoy, el contacto con la naturaleza, con sus seres queridos y una familia que le brindó su apoyo desde el primer momento. Podemos hablar en ese sentido de una matriz afectiva que atraviesa a Aguirre, o como dice Leonor Arfuch, «una articulación entre emociones, sentimientos y memoria personal» (Arfuch, 2018: 24). Quien además agrega:

\footnotetext{
1 Narrativa como perspectiva teórico-metodológica, relevante para la investigación social y también para los estudios literarios. (Arfuch La vida narrada. Memoria, subjetividad y política 2018: 24)

2 Seguí es un municipio distribuido entre los distritos Espinillo y Quebracho del departamento Paraná en la provincia de Entre Ríos. Sus primeras autoridades asumieron el primero de mayo de 1948 . Se encuentra a $50 \mathrm{~km}$ al sudeste de la ciudad de Paraná y su población ronda en los 4500 habitantes.
}

3 Datos extraídos del libro escrito por Horacio Lapunzina La Música y la palabra: diálogos con Carlos Aguirre. 
[...] estas tres características [emociones, sentimientos y memoria personal] nos permiten construir una autobiografía compleja, así como una conciencia extendida, conciencia que supone una mente con un yo. Con ayuda de una memoria autobiográfica la conciencia nos proporciona un yo enriquecido por la propia experiencia individual. (Arfuch, 20I8: 24)

En esta matriz afectiva está el hecho del pueblo, por consiguiente la posibilidad de tener las cosas cerca, refiriéndonos a su familia y seres queridos, y evitar cualquier megalomanía o forma de vanidad que implica la idea de éxito en tanto impacto comunicacional. En este sentido, Aguirre cuenta:

a partir del año 1994, junto con otros dos músicos llamados Luis Barbiero (flautista y compositor) y Ramiro Gallo (violinista y compositor), emprendimos un proyecto que consistía en comenzar a grabar algunos trabajos nuestros, en respuesta al desinterés por parte de algunos sellos discográficos de Buenos Aires en editar nuestras composiciones. Decidimos crear nuestro propio sello, primero editando en formato de casete y luego en CD. Después de unos ańos, nos pareció interesante nuclear esta franja de músicas que en cada provincia tiene su representante, se armó un catálogo, y dichos músicos comenzaron a grabar y editar su música a través de nuestro sello. En estos trabajos podemos nombrar a Jorge Fandermole, «Coqui» Ortiz, Aníbal Sampayo, Walter Heinze, por nombrar algunos. (Aguirre, 20II)

El sello discográfico lleva el nombre de Shagrada Medra, un espacio necesario para difundir la producción de artistas sin los rituales inaccesibles de las discográficas y productoras comerciales. Había una música argentina que necesitaba ser compartida y que no se relacionaba con las banalidades de ciertos mercados musicales. No es casual que el sello surja en medio del menemismo ${ }^{4}$, de un neoliberalismo instalado, entendido como producción independiente y militancia cultural, en defensa de las creaciones e identidades culturales en tiempos de globalización. El común denominador de este sello es el de un trabajo minucioso y paciente por parte de los músicos que se convocan para formar parte del catálogo, los mismos le dan el tiempo que necesita cada producción, es decir, no es una producción vertiginosa y con una necesidad de mercado, sino más bien una que atiende los tiempos creativos. Esta especie de rechazo a

4 El menemismo entendido como movimiento político argentino, liderado por Carlos Saúl Menem quien fue presidente de la Nación Argentina desde 1989 hasta 1999. 
cualquier forma prefabricada de alcance comercial, es algo que el compositor reconoce y donde hay una clara señal de lo que pretende con su arte.

La posibilidad que brinda la música de viajar por diferentes partes del mundo, conocer diversos artistas, paisajes y culturas, también fueron dando forma a esta matriz afectiva, quedando inmersa en un sentimiento de ambigüedad entre local y universal. A raíz de estos viajes ${ }^{5}$, tocar con músicos de distintas partes del mundo fue algo que al compositor le sirvió tanto para sumar conocimientos musicales, como también para alimentar esa experiencia desde abajo del escenario, donde se daba el ámbito ideal para las charlas y reflexiones entre los músicos. De la misma manera, fue muy importante el adoptar una visión más abarcadora del mundo, un tipo de cosmovisión ${ }^{6}$ en el que la comunidad se piense como el conjunto de los seres vivos y el medioambiente no como algo que se lo ve desde afuera, sino siendo parte del mismo organismo.

Una incansable exploración caracteriza la obra de Aguirre, experimentando la química con otros músicos del sonar juntos, dejándose atravesar por esa trama de la amistad y los sonidos, delineando un repertorio que luego quedaría plasmado en discos como Crema (2000), Rojo (2004) y Violeta (2008), cada uno con características muy particulares en cuanto a la búsqueda de nuevos timbres, utilización de instrumentos y también manifestando que es un compositor preocupado por el legado. En medio de estas grabaciones, llega a las manos de la gente un trabajo pensado sólo para un instrumento: el piano. Infinitas músicas e influencias se ven entrelazadas en este CD que lleva el nombre de Caminos (2006), el cual abre una nueva perspectiva en la carrera artística del compositor.

A pesar de que pasaron cuatro años hasta la publicación de su próximo disco que fue Orillania (20I2) y luego cinco más para la de Calma (20I7), Aguirre ha participado en innumerables trabajos de otros compositores, de los que se puede nombrar a Jorge Fandermole, Lucho González, Quique Sinesi, Francesca Ancarola, Juan Quintero, por nombrar algunos. Además, ha colaborado con músicos que, para editar sus trabajos, eligen el sello discográfico

5 Por ejemplo, en el año 1985 Aguirre asiste al «Ill Taller Latinoamericano de Música Popular» con sede en Río de Janeiro, allí tendría la oportunidad de conocer a Hermeto Pascoal y Chico Buarque mediante unos talleres y conciertos que brindaron los mismos. A su vez, tuvo la oportunidad de trabajar durante un tiempo en Chile, llegando a tocar con muchos músicos, entre los que se puede nombrar a Joe Lovano.

6 En este tipo de visión se podría hacer alusión al pueblo andino milenario Aymara, y su concepto de salud que va más allá del bienestar físico y psíquico; sino más bien estar en armonía con la Madre Tierra. Para más información, cf. "Cosmovisión Aymara y su Aplicación Práctica en un Contexto Sanitario del Norte de Chile" de María Paz Valdivia (2006), Revista de bioética y derecho, número 7. 
Shagrada Medra, del cual forma parte, ya sea escribiendo algunos de los arreglos para el músico o también tocando en la grabación, pero todo desde un consenso y un fin artístico entre las dos partes, sin ninguna intención autoritaria, más bien acompañando ese proceso reflexivo que conlleva la grabación de un disco. La carrera artística de Carlos Aguirre es muy extensa, con una trayectoria importante y respetable, todo lo expuesto en esta primera sección fueron algunos aspectos que nos parecían pertinentes resaltar y nombrar, pero a su vez, mucha información biográfica queda por fuera y sin mencionar en nuestra investigación, no por ser menos importante, más bien a fines prácticos de llegar al mejor resultado de nuestros objetivos.

\section{LA INTIMIDAD Y SUS APORÍAS}

Este artículo no pretende definir la intimidad como un término filosófico, sino que se tendrán en cuenta algunos conceptos que sirvan para afrontar el objeto de estudio. Existen muchas definiciones de la palabra intimidad, y a la vez se albergan concepciones erróneas dentro de la misma. «Etimológicamente procede del latín, y más exactamente del adverbio Intus, que es equivalente a dentro» (Sales, 20I2: 4).

En «L'intime», Alain Cugnó dice:

si lo íntimo es el lugar de brote de cualquier manifestación, sólo se ve en la forma de la exterioridad. Lo íntimo es el lugar absolutamente original donde el interior se da como exterior y el exterior como contenido del interior. (Cugnó, 2003: 62I)

Ahora bien, ¿`cómo decir lo íntimo? Como dice Cugnó, la certeza de la intimidad no es una certeza si no se arriesga en el lenguaje. "La implementación de las palabras no consiste en exteriorizar un pensamiento, sino en internalizar palabras pronunciándolas. Las palabras no salen de mí cuando las pronuncio, vienen a mí, llegan a mi pensamiento» (Cugnó, 2003: 62I). Entonces, lo que está tratando de explicar el autor con esta definición es afirmar a la intimidad como algo que se da y se completa sólo en la exterioridad, un pensamiento o sentimiento que existe antes de su expresión pero que necesita ser reafirmado.

Pardo, por otra parte, critica e intenta deshacer los errores que se tienen en torno a la intimidad. En ese sentido, el autor dice: «hay intimidad porque hay 
lenguaje, la intimidad es un efecto del lenguaje» (Pardo, 1998). Estar en intimidad no es estar dentro, sino más bien salir al mayor grado de exposición posible; es estar más afuera de lo que se está en ningún exterior, fuera de sí mismo. Es una manera de entregarse.

Asimismo, Pardo plantea otra problemática, y es que la intimidad reniega con el lenguaje, es decir, que intimidad equivale a inefabilidad, incomunicabilidad, etc. Sería erróneo concebir el lenguaje meramente como un sistema de comunicación o información. Existe un principio de indisociabilidad entre lenguaje e intimidad. La intimidad sólo puede existir comunicándose, cuando hablamos o nos expresamos, lo que no significa que se pueda traducir en términos de información explícita.

En el lenguaje, dice el autor, existen al menos dos dimensiones, el sentido implícito y el significado explícito. Llamaremos significado explícito al que las palabras adquieren a merced de un acuerdo explícito entre los locutores, acuerdo que sí depende de la voluntad de los hablantes. Es el significado público de las palabras, algo que adquieren con el uso.

[...] ninguna palabra puede adquirir un significado «recto» si no es por acuerdo entre locutores, pero ningún acuerdo entre locutores es capaz de rectificar la curvatura interna del sentido. Quienes comparten las mismas resonancias implícitas se sienten partícipes de una misma comunidad lingüística involuntariamente compartida, mientras que quienes pactan acuerdos explícitos constituyen una asociación pública deliberadamente sostenida. (Pardo, 1998: I78)

Por sentido implícito entenderemos todas las connotaciones y «resonancias» internas que acompañan a cualquier palabra dicha. Nadie puede hablar sin que a su vez se le añada a lo dicho un suplemento de sentido implícito que es irreductible al significado explícito. Por lo tanto, la intimidad sería el efecto causado por este ańadido. En el momento en el que traducimos en términos de información explícita la intimidad, según el autor, la misma queda arruinada, malograda, y se convierte en privacidad.

Con estas definiciones proponemos sacar el punto de vista inocente que se tiene en torno a la intimidad, tratando de esclarecer su significado a fin de ser aplicado a nuestro objeto de estudio. En resumen, la intimidad se comunica sólo de una manera, y es que, cuando alguien habla o intenta comunicarse de alguna forma, no solamente nos transmite información explícita, sino que también transmite una resonancia, una serie de elementos que no pueden tra- 
ducirse en información explícita. En este sentido, también entraría en juego la paradoja a la cual hace referencia Cugnó sobre lo íntimo como el lugar original donde «el interior se da como exterior y el exterior como contenido del interior» (Cugnó, 2003: 62I). Se podría hablar de un cierto "estilo», que si lo ubicamos en un campo artístico, no es exactamente lo que se dice, sino la manera en que se lo dice.

\section{El Doble JUEgo DE LA INTIMIDAd}

Nos parece pertinente hablar de otro aspecto que surge en torno a la intimidad y sus aporías. Como dice Arfuch, hoy en día la intimidad aparece en el espacio mediático y en nuestra sociedad de una manera completamente exacerbada y «alcanza grados de máxima intensidad y negatividad» (Arfuch, 20I8: 25), con los reality shows, talk shows, y también en el marketing político. La autora no se pregunta qué son esas emociones, sino más bien qué hacemos con ellas, y manifiesta cierta preocupación por sus alcances éticos y políticos.

En este sentido, podríamos mencionar y acudir al filósofo Walter Benjamin, quien en su escrito Experiencia y Pobreza de 1933 ya hacía alusión a cómo se ha empobrecido la experiencia y también el concepto mismo. Tatiana Staroselsky en su trabajo Consideraciones en torno al concepto de experiencia en Walter Benjamin se refiere al tema y dice:

En este punto, resulta útil realizar una distinción conceptual entre Erlebnis y Erfahrung como dos posibles sentidos de experiencia. Michael Löwy se refiere a estos dos conceptos diferentes de experiencia tal y como aparecen en Benjamin, y describe a la Erfahrung como una «experiencia auténtica [...] fundada en la memoria de una tradición cultural e histórica -» (Löwy, 2005: 29); y la distingue de la Erlebnis como «vivencia inmediata» (Löwy, 2005: 29, 30). En la constatación de Benjamin de la crisis de la experiencia, lo que está en crisis no es la vivencia (Erlebnis), sino la experiencia en el sentido de Erfahrung, aquella que, excediendo el ámbito personal o privado de la mera vivencia, resulta comunicable adquiriendo de ese modo un carácter colectivo o compartido. (Staroselsky, 2015)

Benjamin sostiene que en el mundo en el que vivimos actualmente existe un empobrecimiento de la experiencia y utiliza los dos términos aplicados ante- 
riormente, Erlebnis y Erfahrung. La experiencia de construcción colectiva y de sentido social (Erfahrung) es la que se estaría atrofiando en servicio de otro tipo de experiencia, la que él llama del «nuevo mundo» (Erlebnis), la de las noticias de los diarios o la publicidad, en el cual se transmite una experiencia pero en un sentido aislante, produciendo constantemente la novedad, que al instante en el que nace pierde enteramente sus vínculos con lo anterior y por lo tanto es la simple «novedad de lo aislado, lo inconexo, lo que no tiene precedentes ni consecuencias» (Pardo, 1998).

Pardo hace una reconsideración de estos conceptos y afirma que el artista moderno más bien convierte la pobreza de la experiencia en «experiencia de la pobreza», hace de esa nueva pobreza una genuina experiencia, "hacer de la falta de palabras una palabra, dar la palabra a los que se habían quedado mudos y dejar oír por primera vez su voz desde luego desbaratada y destartalada» (Pardo, 1998). Es decir, el autor piensa que si bien las experiencias que realmente nos movilizan y estimulan nuestra creatividad están siendo abolidas drásticamente con fines completamente vacíos, hay artistas que sin embargo hacen de la pobreza una palabra, y por ende le dan palabras a los sujetos a los cuales se las han quitado. Benjamin no diagnostica una crisis en nuestra percepción, sino en la capacidad de articular los acontecimientos que registramos día a día. "La experiencia no se tiene pasivamente, sino que se hace activamente; no es del orden de lo contemplativo, sino que es acción en la medida en que implica una apropiación y una elaboración de la tradición» (Staroselsky, 20I5: 20I4).

El escrito de Benjamin nos sirve para pensar y poner en juego otra mirada de la intimidad en Aguirre. El compositor llama a las emociones o experiencias, la pregunta sería ¿qué hace con ellas? Como bien explica Staroselsky, se podría decir que la experiencia es un saber que se posee, no un saber científico que necesita ser comprobado, en tanto que remite al sentido común que genera experiencias en la vida. Es necesario diferenciar a la experiencia de la información tal y como circula en los medios de comunicación hoy en día, un tipo de banalización y efectismo tan recurrente en el espectáculo mediático.

Por consiguiente, no debemos pensar que por compartir parte de su intimidad esta tiene un sentido social. Vimos que muchas veces la intimidad se ve envuelta en ese tipo de objetivos aislantes (Erlebnis) que no denotan alcances éticos y constructivos, sino que se encuentra empapada de la clase específica de tiempo que es la cotidianeidad y encerrada en una atmósfera de superficialidad. Como veremos en el marco de la presente investigación, podríamos decir que Aguirre se inserta en una línea de compartir la experiencia o la intimidad 
pero con un sentido de construcción colectiva (Erfahrung), de enriquecimiento espiritual. En efecto, el compositor rompe esta atmósfera y ya no es un sujeto individual que comparte su experiencia, sino un sujeto colectivo que conecta su presente con el pasado estableciendo una relación de «actualización» (por remitir a Benjamin). Implica una interpelación directa, compleja, crítica que el presente le hace al pasado. Hay un gesto constructivo que el presente realiza en su viaje hacia los tiempos pretéritos, y es el modo de reinstalar la experiencia lo que hace capaz de enriquecer su discurso resonando en los demás como un proceso reflexivo, movilizador y creativo.

\section{AnÁlisis}

Volviendo a nuestro objeto de estudio, Carlos Aguirre no busca hacer apología de la universalidad, de ese bagaje musical y cultural que adquirió después de una larga trayectoria, y a su vez cree firmemente en que una persona se completa con vivencias de su lugar, describiéndolo a su modo.

Cuando uno escucha un disco de Aguirre o es partícipe de uno de sus conciertos, su música ofrece sensaciones de intimidad, de cuestiones profundas que se manifiestan tanto en su forma de comunicarse con el espectador, como también en sus puestas en escena. Se toma momentos considerables para dirigirse al público, hasta se podría decir que frena el ritmo acelerado de los tiempos en los que vivimos. Se intensifica la autoconciencia de la audiencia, generándose una situación de introspección que llega a cada una de las personas que se encuentre en ese lugar, un espacio que generalmente es pequeño y donde no es necesario si quiera amplificar los instrumentos acústicos utilizados por el músico, permitiendo escuchar cada elemento sonoro ya sea musical o no, como la respiración misma del artista, que acompańa y hace a la música. Es un artista que vive en el tono que escribe y en el que se entrega.

En Carlos Aguirre se podría decir que existe la noción de intimidad, esa carga de sentido implícito que nombra Pardo, la cual desarrollamos anteriormente. Hay un lenguaje, en ese lenguaje se dicen cosas y se agrega toda una carga de sentido que no se dice, que el emisor no controla pero sin embargo comunica. Estas connotaciones no están enteramente al arbitrio del hablante o, en este caso, del artista.

En todo este lenguaje que mencionamos existe un aspecto fundamental que lo atraviesa y es su matriz afectiva; ese contenido simbólico que él consi- 
dera como estructural, casi como su columna vertebral. Esta matriz se caracteriza por ser algo local y a su vez universal. Es decir, hay un sentimiento de ambigüedad entre estos dos polos. Aguirre nunca se privó de escuchar otras músicas, o de leer diferentes escritores. Lo que ocurre es que muchas de estas características se nos revelan de un modo sutil y no tan explícitamente, al menos a los oídos no tan atentos.

En esta sección, veremos dos piezas instrumentales para piano, un poema y la letra de una canción. Consta decir que nuestra voluntad no es reducir la aplicación de los conceptos solamente a las piezas seleccionadas, las mismas son ejemplos y las herramientas utilizadas son extensibles al resto de la obra. A continuación, vamos a profundizar y detallar algunos aspectos que podrían entrelazarse con la idea de intimidad $y$, a la vez, con lo que llamamos matriz afectiva, analizando un poema escrito por él mismo, situado en el libro del CD Caminos.

Un compañero de búsqueda

la soledad, el fuego

una mañana

el silencio

un brillo tenue y lejano

el abismo

un trueno, un susurro

el campo, los pájaros

la lluvia

una melodía

El misterio de ese generoso universo

que emerge del piano

me conmueve desde muy niño

es así que al calor

de tan preciada intimidad

fue naciendo a través de los años

este primer testimonio de nuestra amistad 
Un compañero de búsqueda, la soledad, el silencio, el abismo, el campo, los pájaros, la lluvia y finalmente una melodía. Podemos denotar como hay una búsqueda de índole interna, de provocar en él mismo una especie de paz interior y de ir al lugar que Cugnó llama «el foro interior, la soledad más original» (Cugnó, 2003: 62I). Luego, llega una melodía, canalizada mediante un generoso universo, haciendo alusión al piano y a la generosidad pensada desde la música misma, como un proceso colectivo o hecho solidario en el que todos aportan para compartir su música, influyéndose los unos a los otros. Algo que lo conmueve desde muy niño, llevándonos a la imagen de su hogar, su familia y la música que de alguna manera respiraba cada día. Finalmente nombra la intimidad como algo preciado que se fue gestando a través de los años, un camino que fue construyendo, andando, y que toma forma de un testimonio, de un canal para comunicar tácitamente o de forma implícita lo que quiere expresar.

Utilizando pocas palabras, podemos observar cómo la resonancia de las mismas se hace sentir; se forma una especie de universo simbólico en torno a cada palabra que Aguirre escribe en su poema, pero a la vez esas cosas tienen carácter mundano, son cosas que le pasan y que vive día a día. Como decíamos anteriormente, Aguirre se completa con vivencias de su lugar e intenta dejar reflejados esos instantes en una pieza musical.

Otro de los puntos que nombra en el poema es su vínculo muy fuerte con la naturaleza. Aguirre es oriundo de una pequeña comunidad rural. En la actualidad habita un espacio que se encuentra muy cercano al río; ese contacto permanente con los relieves naturales de nuestro país, fue generando en Aguirre un marco importante en su vida, que le permitió profundizar su contacto con la música, sin tantas distracciones más allá de su entorno y sus seres queridos. Aguirre busca una intimidad constructiva, la experiencia individual que resuena en lo colectivo, una experiencia vinculada a un sentido de la anterioridad que es jerárquico además de ser cronológico. En este sentido, Starolesky, recuperando a Benjamin, dice que «una experiencia no es cualquier vivencia, ni cualquier encuentro con el mundo: es una elaboración de ese material en la forma de un relato significativo para otros» (Staroselsky, 20I5: 3).

\section{UN PUEBLO de PASO, PEDACITO de Río Y MEMORIA DE PUEBLo}

En esta sección de la investigación pondremos en juego los análisis musicales de las piezas seleccionadas empezando por Un pueblo de paso. 


\section{UN PUEBLO DE PASO}
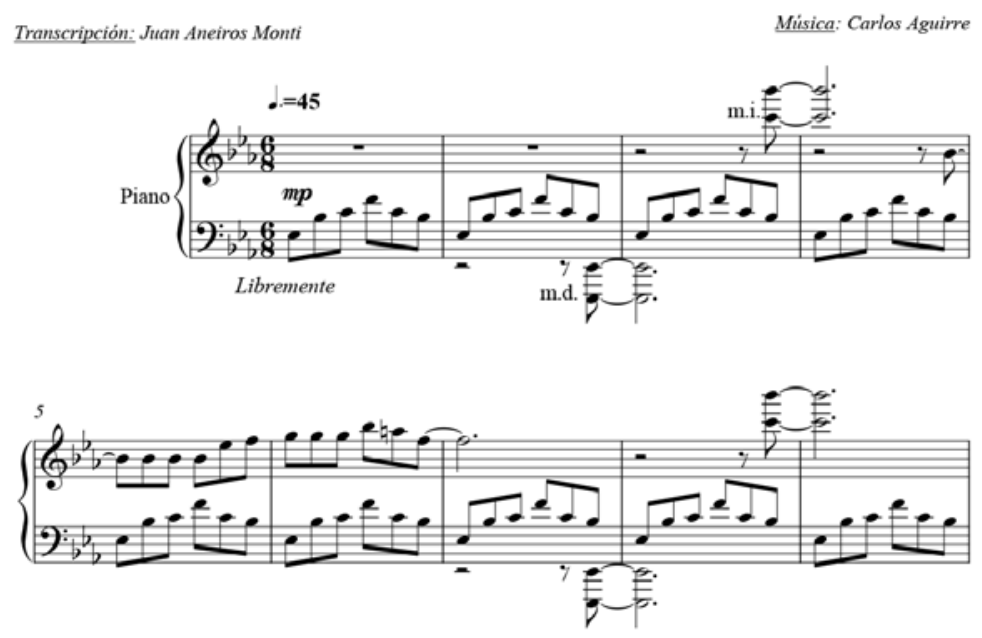

Figura $1 \sim$ Primeros compases de Un pueblo de paso, Track 2 del disco Caminos (2006)

En el título de la pieza la palabra "pueblo» resuena en varios aspectos, hay carga de sentido implícito que se podría relacionar con esa matriz afectiva, con la lejanía o cercanía de aquel tiempo vivido en su pueblo natal Seguí. Otro aspecto que se puede resaltar es la duración de las mismas, en este caso la pieza dura $2^{\prime} 36^{\prime \prime}$, son piezas cortas y con una impronta de tipo canción textural (melodía/ armonía), pero a su vez, podría decirse que hay contrapunto entre mano derecha e izquierda, generando una polifonía de dos líneas que interactúan entre sí (compases 5 y 6). Las secciones son claras, con una forma (A - $\left.\mathrm{A}^{\prime}-\mathrm{B}\right)$, repitiendo la misma por completo pero agregando una coda al final de 5 compases. El tempo de las piezas generalmente suele ser lento, en este caso la negra con punto es igual a 45, no se utilizan adornos y la figura más pequeña utilizada es la corchea, no hay semicorcheas. En cuanto a la armonía, suelen aparecer pasajes de tipo cromático (compases I5 a 2I) pero con una impronta funcional, respetando las cadencias para cerrar las frases y secciones como vemos en el compás 26. La melodía tiene un carácter claro y simple, sin muchos giros y con varias notas repetidas, no superan los tres compases y se mueve generalmente en el registro medio del piano. 

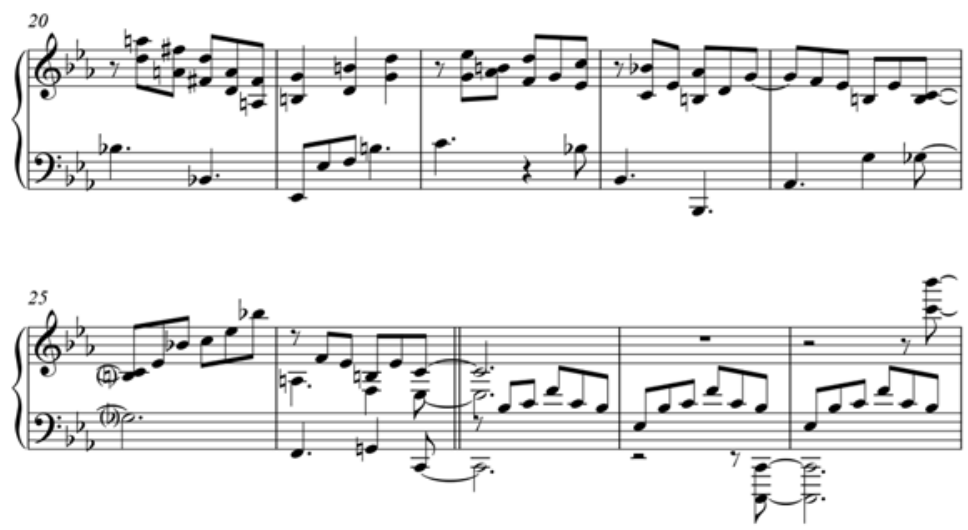

Figura $2 \sim$ Un pueblo de paso, Track 2 del disco Caminos (2006).

\section{Pedacito de Río I}

En la grabación de la pieza se escucha de principio a fin el sonido del agua, se inserta aquí la sensación de un lugar, la proyección de ese universo simbólico, el «río», un lugar tan frecuente en sus canciones. El compositor se refiere al tema diciendo: «durante muchos años sentí que nombraba al río en mis canciones y no lo conocía tan profundamente, sentía que me quedaba grande la palabra, entonces decidí habitarlo y conocerlo más en profundidad, vivir cerca y estar en contacto con la gente que lo habita» (Aguirre, 20I8).

En esta pieza (figura 3) para piano vemos nuevamente una textura de tipo canción (melodía/armonía). La introducción, con el desplazamiento de los arpegios sobre acordes en disposición abierta, acordes que no se definen por completo, pareciera un intento de emular de alguna forma la tranquilidad del río, del movimiento del agua. Nuevamente nos encontramos con una pieza de duración corta, en este caso la duración es de I' $33^{\prime \prime}$, donde se sugiere una melodía simple con repetición de notas, escasa utilización de adornos y frases cortas, que no superan los dos o tres compases. La armonía es de tipo funcional como vemos en la presentación del material melódico (compases 3 a II), pero introduciendo algunos pasajes cromáticos y agregados en los acordes como 9nas, 5 tas aumentadas, I3nas (compases I5 a 22). En este aspecto que señalamos en cuanto a la armonía, podemos observar los universos armónicos por los cuales ha pasado el compositor, recordemos que el jazz, y principalmente los pianistas de jazz, han ejercido gran influencia en su formación. 


\section{Pedacito de río I}
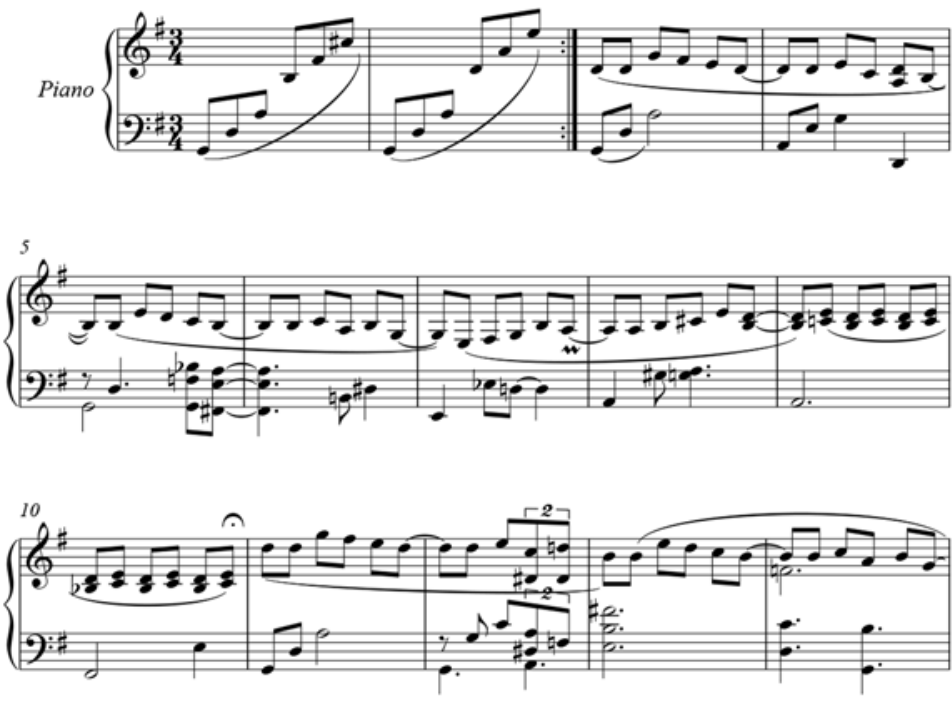

Figura 3 Primeros compases de Pedacito de río I, track 4 del disco Crema (2000).
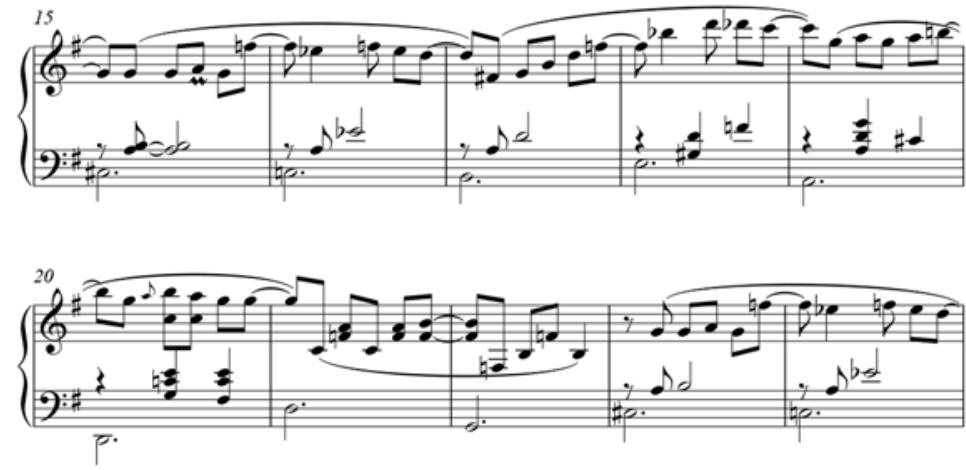

Figura 4 Pedacito de río I, Carlos Aguirre. 


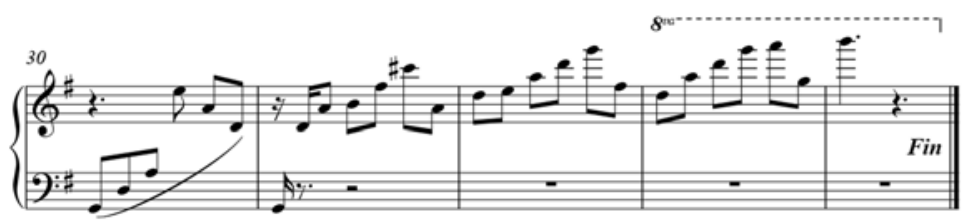

Figura $5 \sim$ Fragmento final de Pedacito de río I.

A modo de cierre de la pieza, Aguirre escribe una pequeña frase que cobra entidad poética: «Pequeño fragmento que surgió de la evocación del río a la distancia» (ver figura 5). Vemos como su entorno (universo simbólico), el lugar que habita y habitó ya hace muchos años, es una importante fuente de inspiración para el compositor, donde se fundan las problemáticas habituales de sus composiciones.

A continuación, se tomará y analizará la letra de Memoria de pueblo del CD Crema (2000), se tomarán algunos fragmentos de la misma que sirven para evidenciar y poner de manifiesto algunas teorías que explicamos anteriormente.

Callecitas de barro

alumbran el tiempo de nuestra niñez;

hondo silencio pueblero

que en las galerías se suele esconder.

Callecitas de barro,

senderos dormidos de aromo y laurel.

[...]

En lágrimas de nubes

anda la tarde penando;

¡ay si pudiera volverme!

¡ay de mi pueblo olvidado!

pero el recuerdo de barro

se queda en la huella del alma nomás.

$[\ldots]$

todo el paisaje que llevo

madura en el hueco de mi corazón

buscando tierno refugio

para que los días no borren su olor.

Todo paisaje que llevo

dibuja en el tiempo su lenta canción. 
En un momento estaba escribiendo y llorando permanentemente, todo el proceso de esta zamba fue así, en un mar de lágrimas, pero desde un lugar entrañable, de sanación. Caí en la cuenta de que necesitaba vivir ese duelo y que nunca lo había expresado. (Aguirre, 2018)

La zamba cuenta con un orgánico de piano y contrabajo, una forma clara de (Intro - A - A' - B) y la misma repitiéndose por completo al finalizar. La utilización del contrabajo es llamativa, ya que sólo se lo utiliza para la interpretación melódica de la introducción y no cumpliendo el rol que generalmente se le da que es el de afirmar las armonías. Se encuentra la idea de austeridad en cuanto a la instrumentación. En esta canción, Carlos Aguirre está contando sus recuerdos, compartiendo la experiencia vivida en su pueblo natal Seguí, haciendo de la memoria una parte indisociable de la experiencia. La infancia de Aguirre pareciera tener una conexión directa con el presente, las imágenes evocadas se plasman en esta canción trayendo consigo una carga afectiva que la interpela: las calles de barro, el silencio pueblero, la niñez, senderos dormidos, una huella afectiva o como llama Arfuch, un «arte memorial» capaz de interpelar la sensibilidad y la responsabilidad de todos nosotros.

\section{RESUltado DEL ANÁLISIS}

Una marca que queda clara en estas tres piezas es la que nosotros llamamos austeridad, señalando la reducción de recursos que se aplican a las mismas. Una austeridad marcada por melodías cortas sin muchos giros, una armonía funcional y la duración - en el caso de las piezas a piano solo - de tiempo más bien cortas. La intimidad se podría pensar bajo el carácter austero que reflejan ciertas obras de Aguirre, una marca que se encuentra a lo largo de su carrera; y en un sentido implícito que cargan los títulos de las piezas. Pensar la intimidad como algo austero va a depender, en términos narrativos, no sólo del qué sino también del cómo se expresa un hecho artístico en particular. Una memoria unida al lenguaje, y el lenguaje unido a la praxis como vehículo para la transmisión de la experiencia. Carlos Aguirre sale al exterior como dice Pardo, pone de manifiesto su intimidad de una manera tanto explícita como implícita en el contenido de Memoria de pueblo, Un pueblo de paso, Pedacito de río I y el poema, llama a sus emociones y las comunica de manera directa o indirecta. 


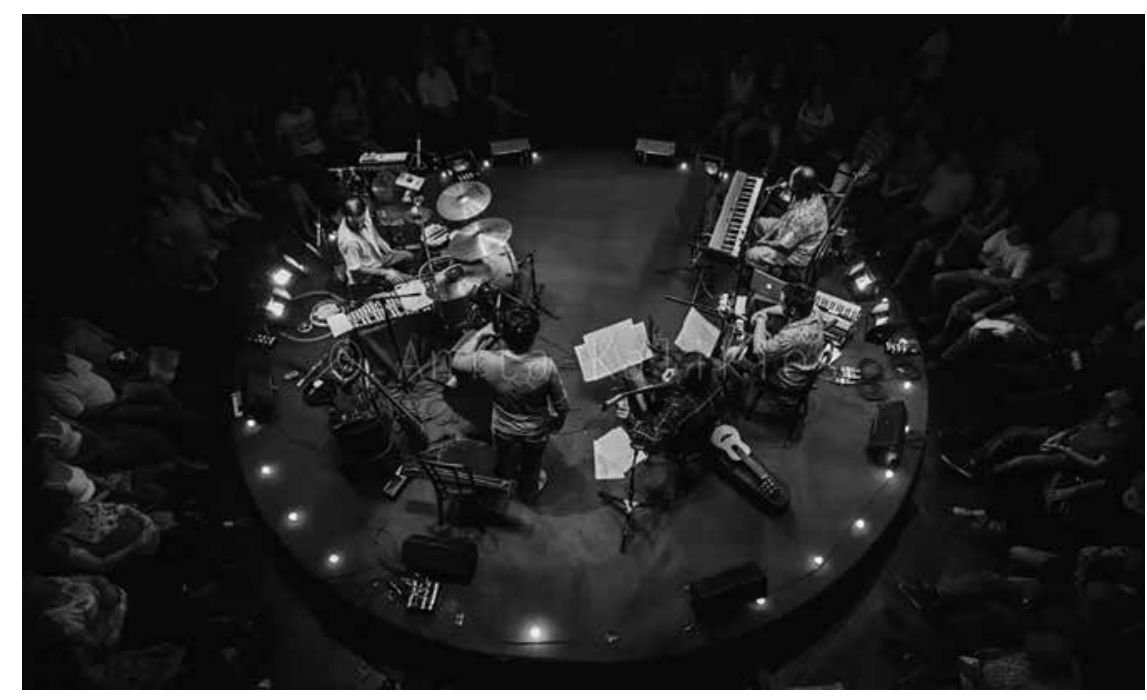

Figura 6 Concierto de Carlos Aguirre (Fotografía: gentileza de Ana Kalikies).

Por otra parte, cabe mencionar las puestas en escena de sus conciertos, en las que se intenta borrar la distancia del escenario con el público, generando aún más el ambiente propicio para la comunicación con el oyente, un aspecto que desde nuestro punto de vista y siendo nosotros mismos testigos al haber concurrido a sus conciertos, es totalmente intencional por parte del compositor (ver figuras 6 y 7 ).

En las figuras 6 y 7 se puede observar la distancia mínima de la audiencia para con los músicos, pareciera ser una cualidad deseable por parte de Aguirre que repite en cada uno de sus conciertos, como en una estructura teatral moderna, donde la búsqueda de la cercanía es una característica importante a tener en cuenta. En este sentido, podemos hablar de un «estilo intimista» como lo llama Luis Puelles Romero, quien además explica:

[...] lo íntimo no es lo intimista. Lo intimista alude a un modo de la caracterización estilística: al que nos referimos cuando, por ejemplo, calificamos de intimista la pintura de Bonnard, Vuillard o Matisse. Mientras que lo íntimo puede, quizás, formularse como categoría estética, lo intimista es una categoría estilística. [...] lo intimo no es lo intimista, si bien se muestra comúnmente a través de esta categoría estilística. (Puelles Romero, I999: 2) 


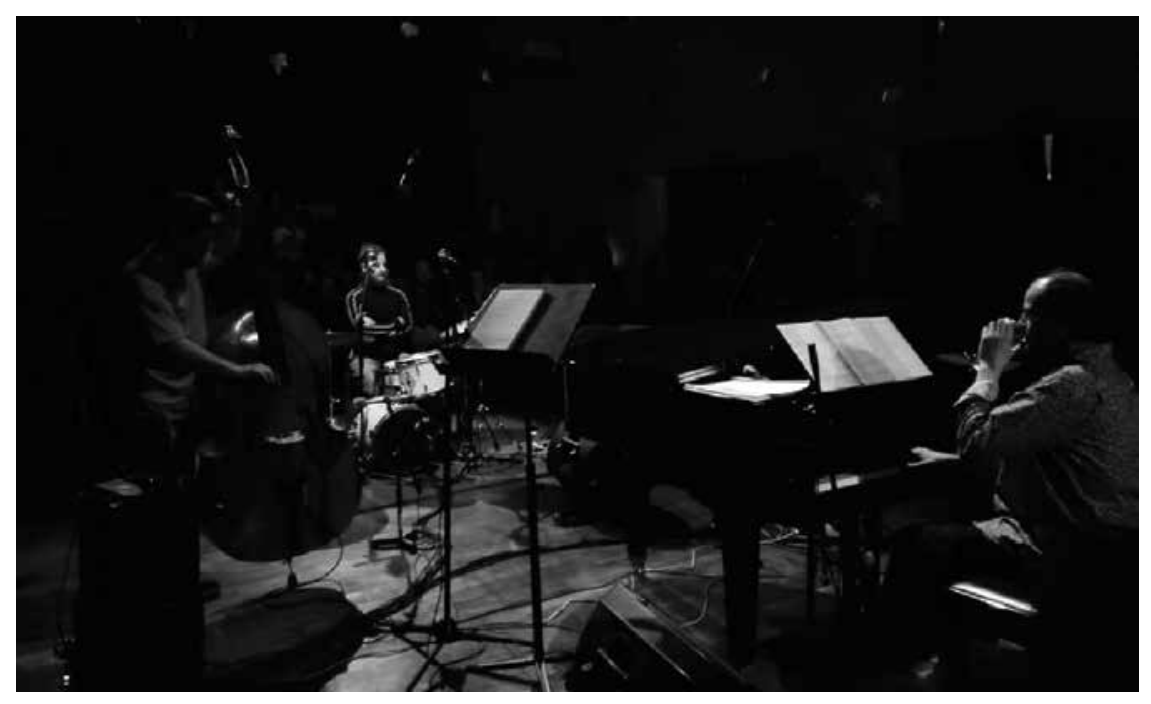

Figura 7 Foto tomada en la presentación del disco Calma en Paraná, Entre Ríos.

Las obras presentadas en este marco, se disponen con un rasgo particular, donde el estilo intimista enmarca a las figuraciones de la intimidad que conlleva dicha obra. Ahora bien, ante esta situación nos preguntamos, si la misma obra se presentara en un ámbito diferente, un lugar donde la convocatoria de público es comúnmente masiva, la obra, ¿perdería su objetivo? ¿Llegaría de la misma manera la experiencia que quiere transmitir el compositor? Una respuesta para estas preguntas sería difícil de concretar, sin embargo, algunas palabras de Hegel podrían aportar a la cuestión:

El arte no está destinado a un corto número de sabios y eruditos; se dirige a la nación entera. Sus obras deben hacerse comprender y gustar por sí mismas, no después de un estudio difícil. De este modo los asuntos nacionales son los más favorables. Todos los grandes poemas, son poemas nacionales. [...] el deber del artista, ante todo, es poner la idea que constituye el fondo en armonía con el espíritu de su siglo y el genio propio de su nación. (Hegel, 2008: 167)

En concordancia con lo dicho anteriormente, las decisiones que el compositor toma en cuanto a dónde presentar su música, no tiene que ver con el público en sí, sino más bien con los circuitos comerciales y las concesiones a 
las cuales les hace frente desde un principio, donde su respuesta más consistente fue la creación de su propio sello discográfico, con una idea que iba creciendo a lo largo del tiempo, estableciendo conexiones entre los músicos que formaban parte del sello lo cual le dio más peso aún, creándose así una especie de colectivo cultural empapado de un arte desenvuelto por completo y con un compromiso ético y social.

\section{Conclusión}

A lo largo de la investigación, se articularon diversos enfoques intentando pensar la complejidad de los temas tratados, cuestiones profundas que nos interpelan en nuestro tiempo. Fueron dos grandes categorías las que se abordaron. Por un lado la intimidad con toda su carga teórica y las aristas que se desprenden de ella. Por otro, la experiencia, asociándola con la intimidad desde una visión narrativa, analizando las implicancias en torno a nuestra interacción con las personas y el mundo.

La palabra, la música y la dimensión simbólica en Carlos Aguirre nos reveló un más allá del contenido expuesto por el compositor, no sólo el contenido sino su fondo, aquello que oculta tanto como muestra, lo que es interior tanto como exterior. En síntesis, mediante los análisis y el estudio de sus obras, pudimos ver cómo existe la noción de intimidad en la medida en que sirve como canal de comunicación, en el que hay una carga de sentido implícito, quedando expuesto en los títulos de las piezas, la austeridad de los recursos implementados en ellas y en la resonancia de las palabras que utiliza tanto en el poema como en la letra de la canción. Mediante esta dimensión implícita, el compositor nos transmite un contenido que tiene tanta relevancia como el del camino explícito. A partir de esto, ya no debemos pensar a la intimidad mediante la significación habitual e inocente que se tiene en torno a la misma, sino ampliando la categoría de su uso teórico-práctico con la que se refiere Pardo.

Aguirre nos muestra un cómo decir, una forma constructiva o, como dice Arfuch, un modo configurativo de la subjetividad, imprimiendo un giro peculiar a la reflexión (Arfuch, 20I8: 58). Un cómo que encierra una memoria, una identidad, un andar lleno de experiencias que se relacionan entre lo personal y lo colectivo. Ese universo que lo constituye no solo llegó y se encuentra en su pensamiento para conmoverlo e inspirarlo, sino que es una idea que sólo podría tomar forma en un proceso de meditación en toda su extensión y profundidad, tomando un alcance de compromiso ético y moral. 
Aguirre dota lo plano de la palabra o de una imagen de una vida de una profundidad específica, como manifestación de una acción, expresión de una interioridad. Pone de manifiesto la existencia de un común, del cual inmediatamente somos partícipes, generando en nosotros la posibilidad de la imaginación, de estimular una reflexión colectiva poniendo freno al aceleramiento sin medida de la vida. Una imaginación que despierte, una imaginación creadora.

\section{Bibliografía}

Arfuch, LeONor. (2018). La vida narrada : memoria, subjetividad y política. Villa María: Eduvim

Benjamin, Walter. (1982). Discursos interrumpidos I. Madrid: Taurus

Cugnó, Alain. (2003). "L'intime», en François Euvé, Études, Tomo 415. Francia: S.E.R, pp. 621-631

FAlú, JuAn. (2011). Cajita de música. Buenos Aires: Fondo Nacional de las Artes Hegel, G. W. F. (2008): Estética, Tomo I. Buenos Aires: Losada

Hernández Sampieri, Roberto. (2004). Metodología de la investigación. México: McGraw Hill

Lapunzina, Horacio. (2007). Música y la palabra : diálogos con Carlos Aguirre. Paraná: Programa Identidad Entrerriana

Oliveras, Elena. (2018). Estética, la cuestión del arte. Ciudad Autónoma de Buenos Aires: Emecé

PARdo, José Luís. (1998). "Políticas de la intimidad: ensayo sobre la falta de excepciones", en Logos, Anales del Seminario de Metafísica, Vol. 32. Madrid: Universidad Complutense de Madrid, pp. 145-196

Pierce, Roger. (1968). "Intimacy in the Theatre", en Educational Theatre Journal, Vol. 20, Tomo II, EE. UU.: The Johns Hopkins University Press, pp. 147-151

ROMERO PUELLES, LUIS. (1999). "Interiores del alma. Lo íntimo como categoría estética", en Concepciones narrativas del yo, Tomo 22. Sevilla: Thémata, pp. 241-247

SALES, CÉCILE. (2012). "Intimacy Issues", en François Euvé: Études, Tomo 416, Francia, S.E.R. pp. 749-759

STAROSELSKY, TATIANA. (2016). "Consideraciones en torno al concepto de experiencia en Walter Benjamin». X Jornadas de Investigación del Departamento de Filosofía FaHCE-UNLP, 19 al 21 de agosto de 2015, Ensenada, Argentina. En Actas X Jornadas (2015). Ensenada: Universidad Nacional de La Plata. Facultad de Humanidades y Ciencias de la Educación. Departamento de Filosofía. Disponible en: http://www.memoria.fahce.unlp.edu. ar/trab_eventos/ev.7648/ev.7648.pdf 


\section{Registro bibliográfico}

Marcelo Gastaldi: "Carlos Aguirre y la intimidad como medio de expresión", en Revista del Instituto Superior de Música, número 17, Instituto Superior de Música, Santa Fe, UNL, República Argentina, 2020, pp. 86-106.

\section{Descriptores / Describers}

Matriz afectiva $\cdot$ intimidad $\cdot$ lenguaje 